\title{
Iniciação científica no Porangabuçu: impressões pessoais
}

\author{
Prolegômenos da pesquisa biomédica na UFC
}

Após vestibular pioneiro com redação e teste somatório de múltiplas escolhas, fui admitido na Medicina da Universidade Federal do Ceará (UFC) em janeiro de 1979. Desde a reforma universitária de 1968, a graduação na UFC previa elenco de disciplinas básicas, ofertadas no campus do Pici (Biologia, Cálculo, Física, Química Geral, Química Orgânica, Sociologia, Bioquímica e Psicologia), seguido das próprias ao curso médico no Porangabuçu. Em julho de 1979, a atividade acadêmica da UFC e até a provinciana cena cultural de Fortaleza foi animada pela $31^{\mathrm{a}}$ Reunião Anual da Sociedade Brasileira para o Progresso da Ciência (SBPC) sob o tema Cante de lá que eu Canto cá com a participação de eminentes pesquisadores, artistas e políticos recém retornados do exílio com a anistia. Assisti encantado vivos debates sobre os principais dilemas do país. Nos trajetos de ônibus até o Pici, ouvia-se falar sobre ciência, cultura e ecologia, tema inédito até então. Vislumbrei ali a verdadeira mentalidade universitária. Sob as mangueiras do Pici, repentistas e o genial Patativa de Assaré se apresentavam. Num clube de subúrbio de Fortaleza, a SBPC promoveu um baile animado por banda de forró, ritmo até então renegado por nós, filhos da burguesia e doravante preferido nas festas.

O ensino médico de então era tocado por docentes sem pós-graduação, na maioria. Muito mais comuns que hoje, atividades práticas contribuíam até na avaliação do desempenho do aluno, mas em geral as aulas eram expositivas. Naqueles tempos préinternet, era raro o acesso a fontes originais da literatura, em especial do estrangeiro. Assim, prevalecia no ensino a opinião do professor, ou magister dixit, cabendo aos alunos memorizar lições do caderno de colegas aplicados. No Porangabuçu, quem tivesse memória enciclopédica era prestigiado. Diferente doutras instituições contemporâneas, como a Faculdade de Medicina de Ribeirão Preto (FMRP-USP), era rarefeita na UFC a pesquisa biomédica. Escasso era a geração de conhecimento, mesmo de afecções autóctones. ${ }^{1}$ Era comum a explicação da terapêutica sob a expressão: "na minha experiência...". Eventuais pesquisadores eram tidos delirantes. Naquele contexto, destacava-se o Departamento de Fisiologia e Farmacologia (DFF) que criara, em 1978, o mestrado em Farmacologia pela iniciativa dos professores Prof. Eduardo Torres, Prof. Hélio Rola, Profa. Glauce Viana, Prof. Luiz Capelo, Prof. Manassés Fonteles e Prof. Marcus Vale.

\section{Batismo de sangue na Fisiologia}

Em 1980.1, já aluno no Porangabuçu, a turma imediatamente anterior promoveu a primeira greve discente da UFC desde os idos de sessenta e oito. Vigorava então na disciplina Fisiologia Humana cruel sistema de avaliação. ${ }^{2}$ A cada aula, um aluno era convocado a palestrar aos colegas sobre o tema do dia, objeto de nota. Ao final, outro era sorteado para corrigir eventuais erros na preleção, recebendo nota proporcional às críticas! Ao cabo de incidentes folclóricos, a turma se recusou a prosseguir. Ante tal impasse, o Prof. Capelo, então subchefe em exercício do DFF, trouxe para mediar a querela dois acadêmicos eminentes: Prof. Wilson Teixeira Beraldo (Universidade Federal de Minas Gerais (UFMG)) e Prof. Nelson Monteiro Vaz (Universidade Federal Fluminense (UFF)). Ao final, acordou-se acabar com tal terror, alocando a turma em 4 subgrupos, cada qual tendo um único docente na disciplina. Assim, no semestre letivo de 1980.2, tive como docente de Fisiologia Humana o Prof. Jorge Romcy. Nas classes dele, reunia times de cinco alunos para estudar capítulos do livro adotado (Guyton), destinando as sextas-feiras para aulas práticas, executadas por ele com a ajuda do respectivo monitor, hoje renomado internista Dr. Paulo Tavares. Por mero acaso, um colega de turma, Gerardo Cristino Filho, hoje docente de Neurocirurgia da UFC em Sobral, convidou-me a assistir um "dia de cão", apelido dado pelo Prof. Capelo aos experimentos no laboratório. De imediato senti nele o enorme carisma, a ampla curiosidade intelectual, a afeição ao livre debate das ideias, os hábitos singelos e o modo franco de tratar a todos. Diferente das demais, a porta do Laboratório do Prof. Capelo estava sempre aberta. Lá as pesquisas eram tocadas pelos graduandos, cabendo aos veteranos realizar cirurgias nos cães e treinar os calouros. Dado o acolhimento, brotava natural senso de companheirismo e até confraternização nos bares, contrapondo eventual desumanização dos calouros quando da inserção na prática médica.

Ademais, encantava o tema da pesquisa do Prof. Capelo, num ambiente quase todo voltado à mera identificação de efeitos farmacológicos de produtos naturais. Médico formado na UFC e Mestre em Fisiologia Renal pela UFMG, Prof. Capelo aventara se o trato gastrintestinal além de dispor de sensores de osmolaridade sanguínea seria capaz de monitorar a volemia. Verificou assim que a distensão mecânica do estômago de cães anestesiados com um balão aumentava a diurese e a natriurese, evitáveis acaso fossem previamente mantidos sob restrição hídrica. No afã de mostrar tal fenômeno ter papel na homeostase, passou a investigar o reverso: o efeito de variações volêmicas agudas no tônus do estômago. Ao frequentar o laboratório, testemunhei experimentos que evidenciaram ser a infusão de salina em cães capaz de aumentar o tônus gástrico enquanto a sangria o diminui, como se o estômago fora reservatório ajustável às demandas por líquido. Ajudando a esfumaçar papel de quimógrafo, anestesiar cães, realizar cirurgias e analisar dados experimentais, logo consegui da UFC bolsa de iniciação científica e fiz minha primeira comunicação em 1982 no $1^{\circ}$ Encontro Universitário de Iniciação à Pesquisa. À época, o laboratório passara a ser co-animado pelo Prof. Hélio Rola, vindo de estágio pós-doutoral em Paris. Médico formado pela UFC, fora o primeiro docente da FAMED a obter ainda em 1966 o grau de Doutor (Bioquímica Médica, Universidade de São Paulo (USP)). Ante dificuldades estruturais em persistir na 
UFC a pesquisa desenvolvida na França, o Prof. Hélio aceitou o apelo de colaboração. Intelectual sagaz, lá introduziu temas como a responsabilidade social da ciência e a autopoiese, idealizada pelo neurobiólogo Humberto Maturana. Trago daí o senso de ser benéfico ao pleno desabrochar da personalidade do aprendiz a convivência com mais de um docente, de temperamentos e aptidões diferentes. Todavia, em dezembro de 1982 houve a infausta perda do Prof. Capelo, em pleno vigor dos 36 anos! Mercê da perseverança tenaz do Prof. Hélio, suplantamos a tragédia e o descaso institucional, voltando a operar cães no "Laboratório Escola Prof. Luiz Capelo", como foi redenominado. Para tal, foi vital recrutar nova leva de alunos de iniciação científica. ${ }^{3}$

Na sequência, viajei em 1985 de ônibus à Ribeirão Preto para representar a UFC no renomado "Curso de Verão" em Fisiologia da FMRP (USP), onde convivi com cientistas de escol, como o Prof. Eduardo Moacir Krieger e o Prof. José Antunes Rodrigues. Aliás, tal evento tivera início nos anos sessenta para entreter leva de alunos do curso médico da UFC que até lá foram, sem avisar, encantados com a Fisiologia Humana, despertado pela prévia estadia em Fortaleza do Prof. Krieger ao assumir, a mando do Diretor da FMRP, Prof. Zeferino Vaz, o ensino da Fisiologia Médica da UFC, vago à época pelo súbito afastamento do catedrático Prof. Aluísio Pinheiro e de seus assistentes. ${ }^{4}$ Em 1985, o curso se deu na forma de experimentos clássicos de Fisiologia, realizados por nós sob ajuda dos pós-graduandos, seguidos de discussões sobre os resultados. Conheci ainda o Museu de Artes de São Paulo e desfrutei da cultura doutras regiões do país. Cativado pela fisiologia, optei então pela carreira acadêmica, e já docente de Fisiologia, tive a ventura de ajudar ao Prof. Ronaldo Ribeiro a criar evento similar na UFC.

\section{Haverá perspectiva para a Iniciação Científica?}

Julgo-me privilegiado ao ter aderido à iniciação científica na sua época de ouro. ${ }^{5}$ Segundo a Academia Brasileira de Ciências, o país exibiu elevação exponencial na produção de artigos científicos nos últimos 20 anos, mercê dentre outros fatores pela prévia expansão da pós-graduação e da iniciação científica, sendo esta de fato criação tupiniquim. Logo, trata-se de parte vital do sistema de C\&T\&I no país, criando um círculo virtuoso. Mas, há quem pense ter tal arranjo no máximo valor pedagógico. ${ }^{6}$ Para transformar a universidade brasileira num efetivo "global player" em termos de C\&T\&I, caberá à academia obter da sociedade a liberação do docente/pesquisador da condição funcional de mero servidor público. De todo modo, urge repensar na UFC a iniciação científica face mudanças notáveis na sociedade e na universidade nos últimos 35 anos. Ante os tempos temerosos de retrocesso institucional no Brasil, tragando o sistema de C\&T\&I a plena entropia, haverá quem considere ingênuo algum planejamento, mas submeto à discussão as seguintes conjecturas para benefício da iniciação científica na UFC. Primeiro, instituir o programa Ciência sem Fronteira, próprio à UFC. Embora seja discutível a versão original de tal programa do governo federal, é consensual a noção que, para o Brasil ter inserção internacional em C\&T\&I e figurar nas redes globais de pesquisa e desenvolvimento, deve haver iniciativas desta natureza. Caberia então à UFC identificar verdadeiros talentos na iniciação científica e obter o financiamento de bolsas junto a instituições parceiras e os enviar ao exterior naqueles países estratégicos ao Brasil. Segundo, instituir o programa Jovens Talentos. Engendrado e sustentado por nós, comunidade acadêmica, a armadilha do sistema de avaliação da CAPES, com prazos rígidos para obtenção dos títulos, fez escassear os projetos de fato inovadores tocados pelos mestrandos e doutorandos. Assim, mediante a identificação de talentos via iniciação científica, a UFC poderia oferecer bolsas de maior prazo (de 2 - 3 anos) para o desenvolvimento de projetos de pesquisa de "alto" risco. Terceiro, instituir o programa MD-PhD. Diferente das ciências básicas, cujos egressos seguem quase somente para a pós-graduação, a maioria daqueles das áreas aplicadas busca primeiro o mercado profissional para só depois voltar à universidade e complementar a formação acadêmica. Tal condição é crítica em especial na Medicina, pela necessidade do treino na residência médica antes de atuar na profissão. Assim, há especialistas, por exemplo neurocirurgiões, que só aos 35-40 anos concluem o Doutorado e passam efetivamente a contribuir na formação de novos recursos humanos. Em países de maior tradição acadêmica, tal dilema foi resolvido via criação do modelo $\mathrm{MD}-\mathrm{PhD}$, onde jovens talentos obtêm da universidade a permissão para interromper provisoriamente a graduação, cursar a pós-graduação em pleno vigor da juventude e só então concluir o curso médico. Há inclusive no Brasil, experiências exitosas, como na Universidade Federal do Rio de Janeiro (UFRJ). ${ }^{7}$ Mesmo na UFC, sabe-se de jovens talentos que ao longo da iniciação científica publicaram mais de um trabalho original em revista científica de prestígio internacional, até como primeiro autor. Evitar-se-ia assim desperdiçar tais talentos, pois boa parte deles desistem da vida acadêmica ao se envolver com as atividades profissionais.

Nesta era onde se propaga o fim do humanismo e a supremacia totalitária do espírito mercantil, ${ }^{8}$ fico com o Eduardo Galeano, a lembrar do benefício da utopia, por nos fazer caminhar, tal qual o horizonte. E assim penso ser o papel da iniciação científica no Brasil.

\section{REFERÊNCIAS}

1. Girão CB. Memória do Hospital das Clínicas. Fortaleza: UFC; 1994.

2. Romcy J, Pereira JM. O simpósio como método didático em Fisiologia Humana - resultados de enquete entre universitários. Rev Med UFC. 1977/78;17/18:103-6.

3. Rola FH. Em memória de Luiz Capelo. Ceará Médico. 1982;4(3):81.

4. Santos AA. A história de um curso de férias [Internet]. 2016 [Acesso em: 27 abr 2017]. Disponível em: https://www.youtube.com/watch?v= ZgUE91VaXt8\&feature=youtu.be

Rev Med UFC. 2017;57(3):9-11. 
5. Marques F. Muito calor, pouca luz. Revista Fapesp. 2009;160:28-31.

6. Amorim DS. Faculdade de Medicina de Ribeirão Preto. A criação da pós-graduação stricto sensu: curso ou área? Medicina (Ribeirão Preto). 2007;40(1):85-92.

7. Oliveira RV, Campos PC, Mourão PA. An MD-PhD program in Brazil: students' concepts of science and of common sense. Braz J Med and Biol Res. 2011;44(11):1105-11.

8. Instituto Humanitas Unisinos. Achille Mbembe: “A era do humanismo está terminando” [Internet]. Revista IHU. 2017 [Acesso em: 27 abr 2017]. Disponível em: http://www.ihu.unisinos.br/564255-achille-mbembe-a-era-do-humanismo-esta-terminando

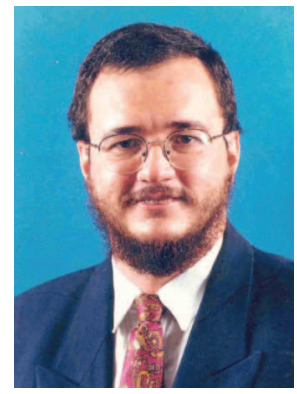

Prof. Dr. Armenio Aguiar dos Santos

Departamento de Fisiologia e Farmacologia

Universidade Federal do Ceará

\section{Como citar:}

Santos AA. Iniciação científica no Porangabuçu: impressões pessoais. Rev Med UFC. 2017 set-dez;57(3):9-11. 